www.nature.com/pj

\title{
Addition-type poly(norbornene)s with siloxane substituents: synthesis, properties and nanoporous membrane
}

\author{
Hiroaki Tetsuka ${ }^{1}$, Mamoru Hagiwara ${ }^{1}$ and Shojiro Kaita ${ }^{2}$
}

Polymer Journal (2011) 43, 97-100; doi:10.1038/pj.2010.99; published online 20 October 2010

Keywords: addition polymerization; palladium catalyst; poly(norbornene); porous membrane; siloxane substituents

\section{INTRODUCTION}

The addition polymerization of bicyclo[2,2,1]hept-2-ene (norbornene, NB) proceeds by double bond opening and leads to a saturated polymer chain with rigid bicyclic rings. The resulting polymer, therefore, exhibits attractive properties such as very high glass transition temperature $\left(T_{\mathrm{g}}\right)$, high optical transparency and low birefringence. However, its poor solubility in common organic solvents and mechanical brittleness are serious disadvantages for the processing the polymer material and severely limit its applications. These drawbacks can be overcome by the introduction of a functional group into the polymer chain. So far, many types of poly(norbornene)s with functional pendant groups have been investigated. ${ }^{1-13}$

Previously, we prepared the addition-type poly(norbornene)s with siloxane ( $\mathrm{Si}-\mathrm{O}-\mathrm{Si}$ ) linkages, which showed improved solubility and mechanical flexibility. ${ }^{13}$ In addition, the film for the polymer with $\mathrm{Si}\left(\mathrm{OSiMe}_{3}\right)_{3}$ groups was found to display high oxygen permeability $\left(P\left(\mathrm{O}_{2}\right)=39-239\right.$ Barrer $)$, depending on the side group content. Recently, Finkelshtein et al. ${ }^{10}$ investigated the addition polymerization of a NB derivative bearing $\mathrm{SiMe}_{3}$ groups and showed that the resulting polymer possessed both high thermal stability and excellent gas permeability $\left(P\left(\mathrm{O}_{2}\right)=980\right.$ Barrer). Thus, incorporation of silicon compounds linked to the main chain can, because of their bulkiness and mobility, improve both the physical and transport properties.

Herein, we report the successful synthesis of poly(norbornene)s with siloxane substituents through the addition polymerization route (Figure 1). The thermal, mechanical and gas permeation properties of the resulting polymers are also presented. In addition, we report the first example of an asymmetric poly(norbornene) membrane, which can be prepared easily and possesses a unique nanoporous structure.

\section{EXPERIMENTAL PROCEDURE}

General procedures and materials

All the experiments involving air- or moisture-sensitive compounds were

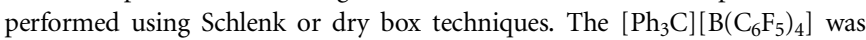
purchased from Strem Co. Ltd and used without further purification. Tricyclohexylphosphine $\left(\mathrm{PCy}_{3}\right)$ was purchased from Wako Pure Chemical Industries Ltd (Osaka, Japan) and used as received. Solvents and NB were purchased from Tokyo Chemical Industrial Co. Ltd (Tokyo, Japan), and degassed under nitrogen and dried over $4-\AA \AA^{2}$ molecular sieves before use. The $5-\mathrm{Si}\left(\mathrm{OSiMe}_{3}\right)_{3}$ norbornene (NBTr), 5-\{SiMe(OSiMe$\left.)_{2}\right\}$ norbornene (NBDi) and $5-\left\{\mathrm{Si}(\mathrm{Me})(\mathrm{Ph})\left(\mathrm{OSiMe}_{3}\right)\right\}$ norbornene $(\mathrm{NBPh})$ were prepared by Shin-Etsu Chemical Co. Ltd, Tokyo, Japan. ${ }^{13}\left(\eta^{3}\right.$-Allyl $)\left(\eta^{5}\right.$-cyclopentadienyl)palladium $((\mathrm{Cp}) \mathrm{Pd}(\mathrm{Allyl}))$ was prepared as described in the literature. ${ }^{14}$

\section{Polymerization of NBs}

A typical polymerization procedure is given below (run 1 in Table 1). (Cp)Pd(Allyl) $\left(18 \mathrm{mg}, 8.0 \times 10^{-5} \mathrm{~mol}\right), \mathrm{PCy}_{3}\left(22 \mathrm{mg}, 8.0 \times 10^{-5} \mathrm{~mol}\right),\left[\mathrm{Ph}_{3} \mathrm{C}\right]$ $\left[\mathrm{B}\left(\mathrm{C}_{6} \mathrm{~F}_{5}\right)_{4}\right]\left(74 \mathrm{mg}, 8.0 \times 10^{-5} \mathrm{~mol}\right)$ and toluene $(30 \mathrm{ml})$ were mixed in a $500-\mathrm{ml}$ flask by manipulation under nitrogen. The catalyst solution was then added to the toluene solution $(270 \mathrm{ml})$ of $\mathrm{NB}(18.8 \mathrm{~g}, 0.2 \mathrm{~mol})$ and $\mathrm{NBTr}(77.8 \mathrm{~g}$, $0.2 \mathrm{~mol}$ ) at room temperature. After $180 \mathrm{~min}$, the mixture was poured into a large quantity of acetone in order to terminate the polymerization. The precipitated polymer was isolated by decantation, washed with acetone and dried under vacuum for $8 \mathrm{~h}$ at $120^{\circ} \mathrm{C}$. The polymer yield was $71 \%$.

\section{Preparation of asymmetric membranes}

Asymmetric membranes for poly(norbornene)s with siloxane substituents were made by a dry/wet-phase inversion technique. The composition of the casting solution was $5 \mathrm{wt} \%$ polymer, $85 \mathrm{wt} \%$ tetrahydrofuran and $10 \mathrm{wt} \%$ methanol. The polymer solutions were filtered and degassed. The solutions were cast on glass plates with a knife gap of $200 \mu \mathrm{m}$ and air-dried there for $10 \mathrm{~s}$. After evaporation, the membranes were coagulated in methanol, washed for $3 \mathrm{~h}$, air-dried for $12 \mathrm{~h}$ and finally dried in a vacuum oven at $120^{\circ} \mathrm{C}$ for $6 \mathrm{~h}$ to remove all solvents.

${ }^{1}$ Silicone-Electronics Materials Research Center, Shin-Etsu Chemical Co. Ltd, Matsuida-machi, Annaka-shi, Gunma, Japan and ${ }^{2}$ RIKEN (The Institute of Physical and Chemical Research), Wako, Saitama, Japan

Correspondence: Dr H Tetsuka, Silicone-Electronics Materials Research Center, Shin-Etsu Chemical Co. Ltd., 1-10 Hitomi, Matsuida-machi, Annaka-shi, Gunma 379-0224, Japan. 


\section{Analytical procedure}

The characterization of polymers was determined by ${ }^{1} \mathrm{H}$ NMR (proton nuclear magnetic resonance; $300 \mathrm{MHz}$ ) and ${ }^{13} \mathrm{C}$ NMR (Carbon-13 nuclear magnetic resonance; $75 \mathrm{MHz}$ ) in $\mathrm{CDCl}_{3}$ with a JNM LA-300WB spectrometer (JEOL Ltd, Tokyo, Japan). Compositions of the obtained copolymers were calculated from ${ }^{1} \mathrm{H}$ NMR spectra on the basis of the peak intensities originating from the siloxane units. All molecular weight data were obtained by gel permeation chromatography at $40{ }^{\circ} \mathrm{C}$, using a TOSOH HLC-8220 GPC system (Tosoh corporation, Tokyo, Japan) with four columns of $\mathrm{H}_{\mathrm{XL}}$ series. Toluene was used as an eluent at a flow rate of $1.0 \mathrm{ml} \mathrm{min}^{-1}$, and a sample concentration of $5.0 \mathrm{mg} \mathrm{ml}^{-1}$ was applied. Polystyrene standards with a low polydispersity (13 standard polystyrene samples: $\left.M_{\mathrm{n}}=5480000-1010, M_{\mathrm{w}} / M_{\mathrm{n}}<1.15\right)$ were used to make the calibration curves. Thermal mechanical analysis experiments were performed using a TMA/SS6000 from SEIKO Instruments, SEIKO Instruments Inc., Chiba, Japan. The cast films of polymer samples were heated from 30 to $400{ }^{\circ} \mathrm{C}$ at $10^{\circ} \mathrm{C} \mathrm{min}^{-1}$ under nitrogen. The tensile strength and elongation at break for the cast films of the polymer were determined using a tensile testing machine (STROGRAPH VE10, Toyo Seiki Seisaku-sho Ltd, Tokyo, Japan) at a crosshead speed of $50 \mathrm{~mm} \mathrm{~min}^{-1}$. The gauge length and the sample width were 20 and $10 \mathrm{~mm}$, respectively. The average of five measured values was taken for each sample. The gas permeability coefficients $(P)$ of the cast films of the polymer were measured using a Rikaseiki K-315-N-01G gas permeability apparatus at $25^{\circ} \mathrm{C}$. The $P$-values were calculated from the slopes of the time-pressure curves in the steady state where Fick's law holds. ${ }^{15,16}$

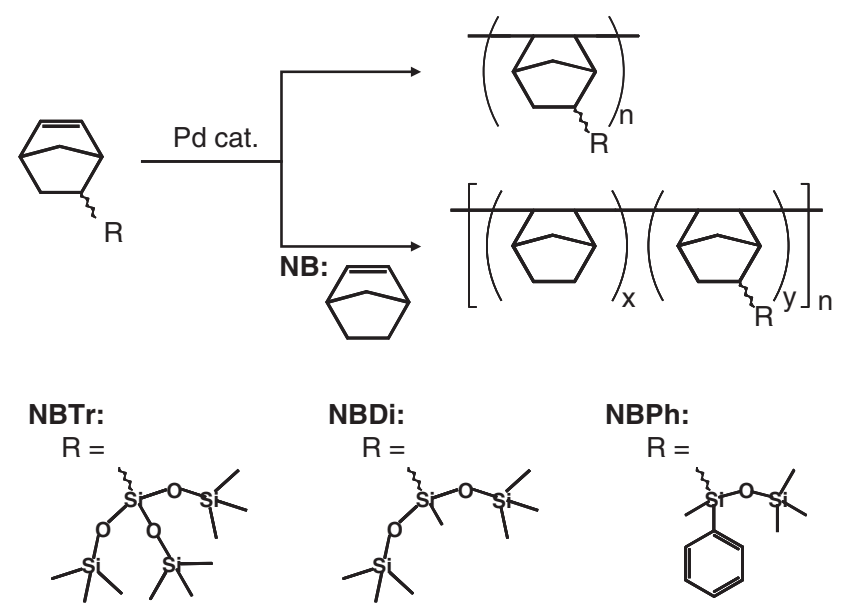

Figure 1 Schematic of polymer preparation.
The gas diffusion coefficients $(D)$ were determined by the time lag method using the equation $D=l^{2} / 6 \theta$, where $l$ is the film thickness and $\theta$ is the time lag, which is given by the intercept of the asymptotic line of the time-pressure curves to the time axis. The gas solubility coefficients $(S)$ were calculated by using the Equation $S=P / D$. Scanning electron microscopy observations for asymmetric membranes were performed using a SEM/S-4700 from Hitachi High-Technologies Corporation (Tokyo, Japan). The scanning electron microscopy samples (on silicone wafers) were sputter coated with $\sim 100 \AA$ of platinum-palladium.

\section{RESULTS AND DISCUSSION}

As a catalyst for addition polymerization of the NB derivatives, NBTr, NBDi and NBPh, the three-component system consisting of (Cp) $\mathrm{Pd}\left(\right.$ ally), $\mathrm{PCy}_{3}$ and $\left[\mathrm{Ph}_{3} \mathrm{C}\right]\left[\mathrm{B}\left(\mathrm{C}_{6} \mathrm{~F}_{5}\right)_{4}\right]$ was employed. This system is already known to be an active catalyst for addition polymerization of NB and its derivatives. ${ }^{11,12}$ Table 1 lists the results of polymerizations that were carried out in toluene. Under these conditions, the catalytic system efficiently initiated homo- and copolymerizations of the NBs. As compared with the binary $\mathrm{Ni}(\mathrm{acac})_{2} / \mathrm{B}\left(\mathrm{C}_{6} \mathrm{~F}_{5}\right)_{3}$ system used before, ${ }^{13}$ the catalytic activity was more than 10 times higher, and the polymers were easily formed. The resulting polymers, except the PNBTr homopolymer obtained in run 3 (Table 1), were all soluble in toluene and tetrahydrofuran. The PNBDi homopolymer and the copolymers from NBTr and NBDi feedings were also soluble in aliphatic solvent such hexane and decane, but insoluble in dichloromethane in contrast with the polymers from NBPh feeding, which showed good solubility in dichloromethane. PNBTr homopolymer was scarcely soluble in common organic solvents. Such behavior is probably attributable to the formation of high-molecular-weight polymer. ${ }^{13,17}$ In fact, even the solvent-soluble polymers have high molecular weights $\left(M_{\mathrm{n}}=467000-842000\right)$ and narrow molecular weight distributions $\left(M_{\mathrm{w}} / M_{\mathrm{n}}=1.24-1.52\right)$.

The formation of these polymers by addition polymerization was confirmed by ${ }^{1} \mathrm{H}$ - and ${ }^{13} \mathrm{C}$ NMR analyses. The compositions of all copolymers were almost proportional to the monomer feed ratios, as determined by ${ }^{1} \mathrm{H}$ NMR spectroscopy. However, high feeding of NB derivative resulted in lower polymer yields. The highest yields of homo- and copolymers were obtained with NBDi, compared with NBTr and NBPh, suggesting that the steric and electronic features of the siloxane substituents have an impact on the catalytic performance, although little in the polymer composition.

Table 1 Homopolymerization and copolymerization of norbornene derivatives

\begin{tabular}{|c|c|c|c|c|c|c|c|}
\hline & & Monomer & & & Composition & & \\
\hline Run & Polymer code & In feed, mol\% & Time, $h$ & Yield, \% & In copolymer, mol\%a & $\overline{\mathrm{M}_{n}} \mathrm{~b}$ & $\overline{\mathrm{M}_{w}} / \overline{\mathrm{M}_{n}} \mathrm{~b}$ \\
\hline 1 & P(NB-co-NBTr)55 & $\mathrm{NB} / \mathrm{NBT} \mathrm{T}=50 / 50$ & 3.0 & 71 & $55 / 45$ & 726000 & 1.51 \\
\hline 2 & P(NB-co-NBTr)37 & $\mathrm{NB} / \mathrm{NBTr}=30 / 70$ & 5.0 & 63 & $34 / 66$ & 601000 & 1.49 \\
\hline 3 & PNBTr & $\mathrm{NBT}=100$ & $3.0^{c)}$ & 45 & & \multicolumn{2}{|c|}{ Insoluble } \\
\hline 4 & P(NB-co-NBDi)55 & $\mathrm{NB} / \mathrm{NBDi}=50 / 50$ & 0.25 & 75 & $54 / 46$ & 842000 & 1.52 \\
\hline 5 & P(NB-co-NBDi)37 & NB/NBDi $=30 / 70$ & 1.0 & 70 & $33 / 67$ & 724000 & 1.38 \\
\hline 6 & PNBDi & $\mathrm{NBDi}=100$ & 2.0 & 55 & & 632000 & 1.39 \\
\hline 7 & P(NB-co-NBPh)55 & $\mathrm{NB} / \mathrm{NBPh}=50 / 50$ & 3.0 & 60 & $53 / 47$ & 736000 & 1.24 \\
\hline 8 & P(NB-co-NBPh)37 & $\mathrm{NB} / \mathrm{NBPh}=30 / 70$ & 5.0 & 51 & $35 / 65$ & 479000 & 1.32 \\
\hline 9 & PNBPh & $\mathrm{NBPh}=100$ & $3.0^{c}$ & 48 & & 467000 & 1.35 \\
\hline
\end{tabular}

Abbreviations: (Cp)Pd(Allyl), ( $\left.\eta^{3}-A l l y l\right)\left(\eta^{5}\right.$-cyclopentadienyl)palladium; GPC, gel permeation chromatography; ${ }^{1} \mathrm{H}$ NMR, proton nuclear magnetic resonance; NB, norbornene; NBDi, 5-\{SiMe $\left.\left(\mathrm{OSiMe}_{3}\right)_{2}\right\}$ norbornene; NBPh, 5-\{Si(Me)(Ph)(OSiMe 3$\left.)\right\}$ norbornene; NBTr, 5-Si(OSiMe 3$)_{3}$ norbornene; $\mathrm{PCy}_{3}$, tricyclohexylphosphine; THF, tetrahydrofuran.

aDetermined by ${ }^{1} \mathrm{H}$ NMR spectroscopy.

betermined by GPC vs polystyrene standards in THF.

cPolymerization was carried out at $50^{\circ} \mathrm{C}$.

CPolymerization was carried out at $50^{\circ} \mathrm{C}$.
Conditions: in toluene; total volume $=300 \mathrm{ml}$; room temperature; $[(\mathrm{Cp}) \mathrm{Pd}(\mathrm{Allyl})] /\left[\mathrm{PCy} y_{3}\right] /\left[\mathrm{Ph}_{3} \mathrm{C}\right]\left[\mathrm{B}\left(\mathrm{C}_{6} \mathrm{~F}_{5}\right)_{4}\right]=1 / 1 / 1 ;[\text { monomers }]_{0} /[\text { catalyst }]_{0}=5000$. 
Table 2 Thermal, mechanical, and transport properties of the cast films of the solvent for poly(norbornene)s with siloxane substituents

\begin{tabular}{|c|c|c|c|c|c|}
\hline Polymer code & $\mathrm{T}_{g}\left({ }^{\circ} \mathrm{C}\right)^{\mathrm{a}}$ & Tensile strength at break $(\mathrm{Mpa})^{\mathrm{b}}$ & Elongation at break $(\%)^{\mathrm{b}}$ & $P\left(\mathrm{O}_{2}\right)(\text { Barrer })^{\mathrm{c}}$ & $D\left(O_{2}\right)\left(10^{-7} \mathrm{~cm}^{2} \mathrm{~s}^{-1}\right)^{\mathrm{d}}$ \\
\hline $\mathrm{P}(\mathrm{NB}-\mathrm{co}-\mathrm{NB} \operatorname{Tr}) 37$ & 318 & 18 & $<3$ & 360 & 11.1 \\
\hline P(NB-co-NBDi)55 & 268 & 33 & 7 & 66 & 8.4 \\
\hline $\mathrm{P}(\mathrm{NB}-\mathrm{co}-\mathrm{NBDi}) 37$ & 271 & 28 & 8 & 107 & 12.3 \\
\hline PNBDi & 282 & 22 & 16 & 303 & 62.2 \\
\hline PNBPh & 298 & 32 & 7 & 41 & 6.2 \\
\hline
\end{tabular}

Abbreviations: $T_{\mathrm{g}}$, glass transition temperature; TMA, thermal mechanical analysis

aDetermined by TMA analysis.

betermined by tensile test, film thickness $=0.1 \mathrm{~mm}$.

${ }^{c} P$ : permeability coefficient. Barrer (1 Barrer $=10^{-10} \mathrm{~cm}^{3}\left(\right.$ STP) $\mathrm{cm}$ per $\mathrm{cm}^{2} \mathrm{~s} \mathrm{~cm} \mathrm{Hg}$ ).

${ }^{\mathrm{d}} D$ : diffusion coefficient, $10^{-7} \mathrm{~cm}^{2} \mathrm{~s}^{-1}$.

Table 2 lists the thermal and mechanical properties of the poly (norbornene)s with siloxane substituents. By casting a polymer solution onto glass, transparent and self-standing films for all soluble polymers were prepared. According to thermal mechanical analysis, the polymers had very high $T_{\mathrm{g}}$ in the range of $255-318^{\circ} \mathrm{C}$, which were dependent on the structure and content of the side groups. Although the polymers had very high $T_{\mathrm{g}}$, the films displayed good flexibility at room temperature. The tensile test showed that at high side group content in polymers, the elongation at the break increased, whereas the tensile strength tended to decrease. The polymers with NBPh units possessed the highest tensile strength.

The gas permeation property of the poly(norbornene)s with siloxane substituents was evaluated by monitoring the oxygen permeability of their films. As shown in Table 2, the oxygen permeability of the polymers depended on the contents of the side groups and generally increased with high side group content in polymers. Although a slight change was observed for the $P\left(\mathrm{O}_{2}\right)$ value of the polymers with $\mathrm{NBPh}$ units, the $P\left(\mathrm{O}_{2}\right)$ value greatly increased for the polymers with NBTr and NBDi units. The $P\left(\mathrm{O}_{2}\right)$ values of $\mathrm{P}(\mathrm{NB}-\mathrm{co}-\mathrm{NBTr}) 37$ and PNBDi reached 360 and 303 Barrer, respectively. However, it is of interest to note that PNBDi had a very high $D\left(\mathrm{O}_{2}\right)$ value compared with $\mathrm{P}(\mathrm{NB}-$ co-NBTr)37, despite having a comparable $P\left(\mathrm{O}_{2}\right)$ value. These results suggest that the structures of siloxane substituents have a decisive role in the gas transport properties of the polymer films. ${ }^{10,17-19}$

Asymmetric membranes for poly(norbornene)s with siloxane substituents were prepared by a dry/wet-phase inversion process. In general, asymmetric membranes made through this technique consist of a thin skin layer supported by a porous substructure. ${ }^{20,21}$ Such a structural system is suitable for gas separation and ultrafiltration applications. Figure 2 shows a scanning electron micrograph of a typical structure for the $\mathrm{P}(\mathrm{NB}-\mathrm{co}-\mathrm{NBTr}) 37$ membrane. The cross section of the membrane consisted of the thin skin layer and the porous substructure. The substructure was characterized by a spongelike structure containing large microvoids. The structural features of the membranes for all poly(norbornene)s with siloxane substituents were similar.

The surface structures of the skin and porous layers for asymmetric $\mathrm{P}(\mathrm{NB}-\mathrm{co}$-NBTr) 37 membrane are shown in Figure 3. Although the large pores with diameters of $\sim 50 \mu \mathrm{m}$ were formed in the surface porous layer, the skin layer possessed the ultrafine pores with diameters in the range of $20-100 \mathrm{~nm}$. The nanometer-sized pores were distributed over the surface skin layer (see Figures $2 \mathrm{~d}$ and $3 \mathrm{c}$ ). For the membranes of polymers with NBTr and NBDi units, similar
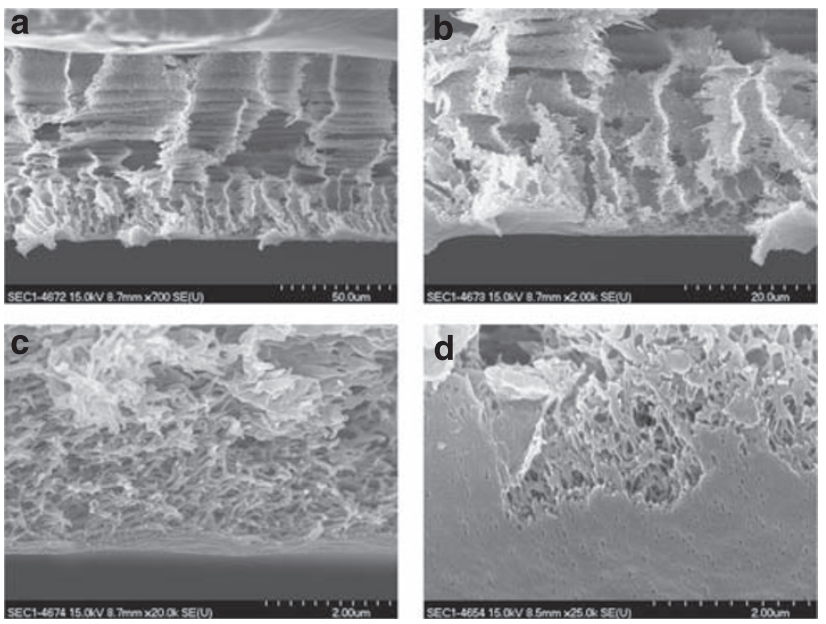

Figure 2 Cross section of asymmetric P(NB-co-NBTr)37 membrane: (a) asymmetric membrane, (b) magnified image of a, (c) skin layer (magnified image of $\mathbf{b}$ ) and (d) skin layer from a different angle.
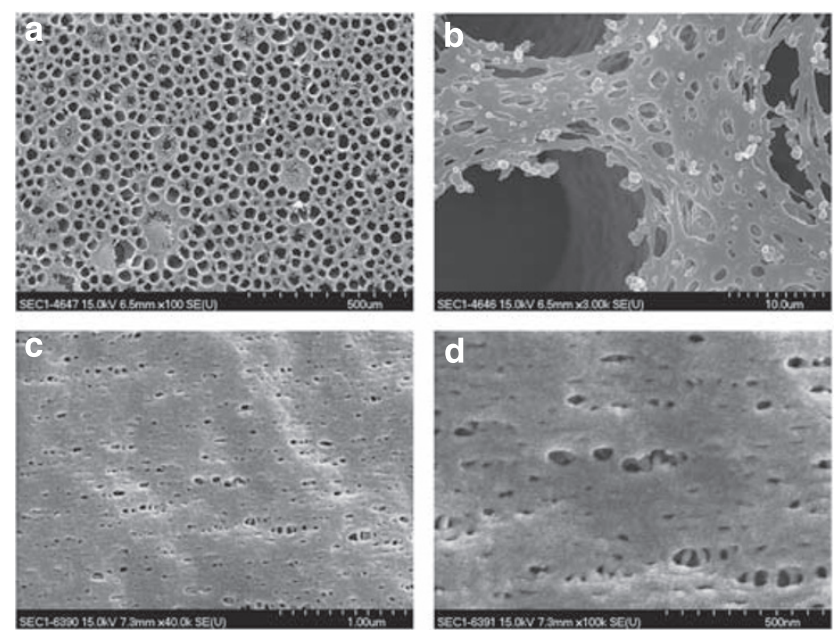

Figure 3 Surface structures of asymmetric P(NB-co-NBTr)37 membrane: (a) porous layer, (b) magnified image of a, (c) skin layer and (d) magnified image of $\mathbf{c}$. 
nanoporous structures were observed. Unlike the polymers, any of the polymers with NBPh units formed a pore-free, dense skin layer under these conditions. The results suggest that the nature of the substituents affects the nano- and microphase separation behaviors, which leads to the formation of asymmetric membrane, ${ }^{20}$ and that the membrane surface structure can be tuned by employing appropriate substituents.

\section{CONCLUSION}

Addition-type poly(norbornene)s with siloxane substituents were successfully synthesized using the (Cp)Pd(ally) system. The polymers had very high $T_{\mathrm{g}}$ of up to $255^{\circ} \mathrm{C}$, and their films displayed high flexibility. The $T_{\mathrm{g}}$ and mechanical properties were dependent on the content and structure of the siloxane substituents. In addition, the gas permeabilities of the polymer films also varied with the content and structure of the siloxane substituents, and the films for the polymers with branched side groups showed high oxygen permeability $\left(P\left(\mathrm{O}_{2}\right)=66-\right.$ 360 Barrer). Asymmetric poly(norbornene) membranes were first prepared by a dry/wet-phase inversion technique. The membranes consisted of the thin skin layer supported by the porous substructure, and the surface skin layer had a unique nanoporous structure related to the nature of the side groups. The findings of this study suggest that the structure of the side group linked to the chain is an important factor for the regulation of the material properties and presents a new possibility for the application of poly(norbornene) materials.

\section{ACKNOWLEDGEMENTS}

We thank Mr K Iwase, of DENSO Corporation, for useful discussions. We appreciate the assistance provided by Ms E Takita in the scanning electron microscopy observations and by Dr Y Yamane in the NMR measurements; both are at Shin-Etsu Chemical Co. Ltd.

1 Breuning, S. \& Risse, W. Transition-metal-catalyzed vinyl addition polymerizations of norbornene derivatives with ester groups. Macromol. Chem. 193, 2915 (1992).

2 Goodall, B. L., Benedikt, G. M., McIntosh, L. H., Barnes, D. A. \& Rhodes, L. F. Addition polymers derived from norbornene-functional monomers and process therfor. International Patent WO 95/14048 (1995).
3 Reinmuth, A., Mathew, J. P., Melia, J. \& Risse, W. ( $\eta^{3}$-Allyl)palladium(II) catalysts for the addition polymerization of norbornene derivatives with functional groups. Macromol. Rapid Commun. 17, 173 (1996).

4 Goodall, B. L. Addition polymers of polycycloolefines containing functinal substituents. International Patent WO 96/37526 (1996).

5 Dorkenoo, K. D., Peromm, P. H. \& Rezac, M. E. Gas transport properties of a series of high $T_{\mathrm{g}}$ polynorbornenes with aliphatic pendant groups. J. Polym. Sci. B Polym. Phys. 36, 797 (1998)

6 Heinz, B. S., Alt, F. P. \& Heitz, W. Pd(II)-catalyzed vinylic polymerization of norbornene and copolymerization with norbornene carboxylic acid esters. Macromol. Rapid Commun. 19, 251 (1998).

7 Grove, N. R., Kohl, P. A., Allen, S. A. B., Jayaraman, S. \& Shick, R. A functionalized polynorbornene dielectric polymers: adhesion and mechanical properties. J. Polym. Sci. B Polym. Phys. 37, 3003 (1999).

8 Janiak, C. \& Lassahn, P. G. The vinyl homopolymerization of norbornene. Macromol. Rapid Commun. 22, 479 (2001).

9 Shin, B. G., Jang, M. S., Yoon, D. Y. \& Heitz, W. Vinyl-type polymerization of norbornene dicarboxylic acid dialkyl esters. Macromol. Rapid Commun. 25, 728 (2004).

10 Finkelshtein, E. S., Makovetskii, K. L., Gringolts, M. L., Rogan, Y. V., Golenko, T. G., Starannikova, L. E., Yampol'skii, Y. P., Shantarovich, V. P. \& Suzuki, T. Addition-type polynorbornenes with $\mathrm{Si}\left(\mathrm{CH}_{3}\right)_{3}$ side groups: synthesis, gas permeability, and free volume. Macromolecules 39, 7022 (2006).

11 Kaita, S., Matsushita, K., Tobita, M., Maruyama, Y. \& Wakatsuki, Y. Cyclopentadienyl nickel and palladium complexes/activator system for the vinyl-type copolymerization of norbornene with norbornene carboxylic acid esters: control of polymer solubility and glass transition temperature. Macromol. Rapid Commun. 27, 1752 (2006).

12 Wakatsuki, Y. \& Kaita, S. Method for producing norbornene based addition (co)polymer. International Patent WO 06/64814 (2006).

13 Tetsuka, H., Isobe, K. \& Hagiwara, M. Synthesis and properties of addition-type poly(norbornene)s with siloxane substituents. Polym. J. 41, 643 (2009).

14 Tatsuno, Y., Yoshida, T. \& Otsuka, S. ( $\eta^{3}$-Allyl)palladium(II) complexes. Inorg. Synth. 19, 220 (1979).

15 Barrer, R. M. \& Rideal, E. K. Permeation, diffusion and solution of gases in organic polymers. Trans. Faraday Soc. 35, 628 (1939).

16 Stern, S. A. in Membrane Separation Processes (ed. Meares, P.) (Elsevier, New York, 1976).

17 Katsumata, T., Shiotsuki, M., Sanada, F. \& Masuda, T. Synthesis and properties of polynorbornenes bearing oligomeric siloxane pendant groups. Polymer 50, 1389 (2009).

18 Zhao, C. T., do Rosário Ribeiro, M., de Pinho, M. N., Subrahmanyam, V. S., Gil, C. L. \& de Lima, A. P. Structural characteristics and gas permeation properties of polynorbornenes with retained bicyclic structure. Polymer 42, 2455 (2001).

19 Bondar, V. I., Kukharskii, Y. M., Yampol'skii, Y. P., Finkelshtein, E. S. \& Makovetskii, K. L. Permeation and sorption in polynorbornenes with organosilicon substituents. J. Polym. Sci. B Polym. Phys. 31, 1273 (1993).

20 Pinnau, I., Wind, J. \& Peinemann, K. V. Ultrathin multicomponent poly(ether sulfone) membranes for gas separation made by dry/wet phase inversion. Ind. Eng. Chem. Res. 29, 2028 (1990).

21 Kawakami, H., Mikawa, M. \& Nagaoka, S. Gas permeability and selectivity through asymmetric polyimide membrane. J. Appl. Polym. Sci. 62, 965 (1996). 